\title{
A Continuous Nonlinear Fractional-Order PI Controller for Primary Frequency Control Application
}

\author{
Kamal Elyaalaoui, Moussa Labbadi (iD, Mohammed Ouassaid, and Mohamed Cherkaoui \\ Department of Electrical Engineering, Mohammadia School of Engineers, Mohammed V University in Rabat, Rabat, Morocco \\ Correspondence should be addressed to Moussa Labbadi; moussalabbadi@research.emi.ac.ma
}

Received 12 March 2021; Revised 27 March 2021; Accepted 31 March 2021; Published 13 April 2021

Academic Editor: Liping Chen

Copyright (C) 2021 Kamal Elyaalaoui et al. This is an open access article distributed under the Creative Commons Attribution License, which permits unrestricted use, distribution, and reproduction in any medium, provided the original work is properly cited.

\begin{abstract}
In this paper, a nonlinear fractional-order PI (NL-FO-PI) controller is proposed for primary frequency control (PFC) of a wind farm based on the squirrel cage induction generator. The new structure composites a fractional-order operator and nonlinear function to achieve better control performance for the PFC system. The benchmarking process is demonstrated by investigating the performance of fractional-order PI (FO-PI) and nonlinear PI (NL-PI) controllers. Initially, the controller is applied to a single-area power system for design and stability study and then extended to the two-area interconnected wind farm to validate the applicability in the more realistic power system. The proposed control method ensures the balance of power and keeps the system frequency within a suitable range. The simulation results demonstrate that the proposed NL-FO-PI controller provides less percentage overshoot, settling time, rise time, and peak time than other controllers.
\end{abstract}

\section{Introduction}

1.1. Background and Motivation. In modern power network stabilization, the amount of power generated and that consumed must always be balanced. The imbalance between the load and the power generation leads to system instability. Therefore, the power system should have enough power reserve to support the imbalance of power and maintain the power system stability $[1,2]$. The frequency stability is affected by the electric vehicles [3]. Participation in the service system is becoming more and more demanded for a decentralized power generation [4]. Therefore, large-scale wind energy conversion systems are required to provide primary frequency control (PFC) $[2,5,6]$. The main objective of PFC is to keep the frequency within the specified limits required by several grid operators [7]. To achieve the PFC objectives, the wind turbines must have a sufficient reserve of kinetic energy stored in the rotating mass of their blades or using a storage system [8]. The high performances of the PFC are obtained using the superior and advanced controller. Several control methods are being proposed for the wind power plants $[9,10]$. In the study by Cherkaoui et al. [2], the PI-Fuzzy-PI was implemented for best response compared to linear control. The nonlinearities of the power systems [11] in LFC include the frequency dead band and rate constraint of the generator, which required robust nonlinear control and advanced control systems.

1.2. Literature Review. In recent years, the advancement in the research field of advanced control is oriented towards the use of fractional calculus to improve the performance of the control loop, which leads to rising of noninteger controllers more flexible than others [12]. The fractionalorder PI (FO-PI) controller, which is a generalization of the classical PI corrector, has been proposed in many works [12-14]. The control system based on fractional-order integral and derivative is investigated in many fields of engineering such as quadrotor [15] and renewable energy conversion system $[13,14,16]$ to ensure fast convergence to the desired value and high precision. The fractional-order 
operators offer the additional parameters (two degrees of freedom) for more flexibility of the controller and additional performance in the control design. The fractionalorder fuzzy PI (FOFPI) controller can be used to improve the control performance of a grid-connected Variable Speed Wind Energy Conversion System [17-25] and to establish a stable operation of the electric system with automatic generation control [26]. Another well-known fractional control algorithm is the fractional-order PID controller (FOPID) used in many applications to overcome the problem related to the dynamic system response and performances $[27,28]$. In references [29, 30], a variable coefficient fractional-order controller is proposed. This controller type can be used for renewable system control $[31,32]$ and intelligent control systems and to improve performance of building structure vibration [33]. The stability of FOC can be verified using the root-locus method [34, 35]. But, the FO-PI cannot sufficiently improve the performance (response time, rise time, and stability) and robustness against noise and interference [36-38], which demands the use of the Nonlinear PI (NLPI) controller with the fractional-order operator [39]. Unlike the conventional PI controller, which can solve the problem of constant disturbance rejection only, the NL-PI controller has the ability to reject disturbance of arbitrary shape. The combination of FO-PI and NL-PI in one structure offers a superior performance [40]. In references $[41,42]$, the stability analysis of NL-FO-PI demonstrates the system stability and the convergence of the system variables to their desired values. The real-time implementations of FO-PI and NL-PI controllers are given in references [43-45].

1.3. Contribution. The comparison with the FO-PI and NLPI controllers shows a clear improvement in the performance of response time and stability of the proposed NLFO-PI controller (less percentage overshoot, settling time, rise time, and peak time). The best response can be obtained using the optimization algorithms [46]. This proposed control method allows the WF based on the squirrel cage asynchronous generator (SCAG) to participate effectively in the primary frequency control.

The main contributions of this paper are as follows:

(i) Unlike the conventional NL-PI and FO-PI controllers, the proposed control method offers additional degree of freedom for more flexibility

(ii) Designing of the new NL-FO-PI controller for primary frequency control, which has the same advantages of the classical PI control such as simplicity of design and easy for implementation

(iii) Ensuring a primary reserve for a quick maintaining of power balance and offering of high convergence rate and accuracy for frequency stabilization

(iv) Developing the model of the two-area power network for frequency control using the wind farm active power
1.4. Paper Organization. In Section 2, we present test system modeling. The proposed NL-FO-PI controller is applied to primary frequency control in Section 3 with its design and synthesis structure. Section 4 presents the simulation results for primary frequency control. Finally, the conclusion is given in Section 5.

\section{Test System Modeling}

The power system modeled in this paper consists of the wind farm aggregated model and power network model. It is modeled using MATLAB/Simulink software. The wind farm, presented in Figure 1, is based on the squirrel cage induction generator connected into the grid. The rated power of WF is $90 \mathrm{MW}$. The WTs of WF are identical (same operating points of the WTs) and receive the identical wind velocity (same incoming wind speed). Therefore, the adequate model for this kind of WF is the full-aggregated model (FAM) [47, 48]. All WTs within WF and their internal electrical network are modeled using one equivalent WT (Equi_WT).

The grid is an extensive system divided into areas. Each area consists of a steam turbine equipped with a synchronous generator as shown in Figure 2. The power system consists of two 200-MVA synchronous generators. Each generator incorporates an automatic voltage regulator to control the reactive power flow and a speed control system for active power flow control. The balance power and the constant generator speed are achieved for load power references of $P_{\text {ref- } 1}=0.674 \mathrm{pu}$ and $P_{\text {ref- } 2}=0.6739 \mathrm{pu}$. The increase of load power ( $P_{L}$ is connected) leads to deceleration of generators and frequency drop. In this case, the WF must take part to maintain the frequency constant and ensure the balanced power.

\section{Primary Frequency Control Design}

3.1. Primary Frequency Control and the Grid Code Requirements. According to grid codes, the wind farms must remain connected to the grid and participate in frequency control. European TSO (ENTSO-E) imposes for the WT to satisfy the characteristic of the active power response versus the frequency deviation and time for full activation presented in Figure 3.

A fast active power response (injection) is required immediately after a frequency deviation which demands a regulating reserve of active power [49]. The primary reserve is intended to be the additional power capacity and created at the deloaded power operation $\left(P_{\mathrm{del}}\right)$, as shown in Figure 4 [2]. It is activated automatically after a few seconds of an imbalance between the demand and the supply of electricity on the grid. The objective of the primary reserve is to quickly maintain a balance between energy production and consumption and to stabilize the frequency at the nominal value.

3.2. Fractional-Order Preliminaries. Fractional calculus is a generalization of integral and derivative operators to obtain the fundamental noninteger operator $D_{t}^{\alpha}$. The continuous integral differential operator is defined as 


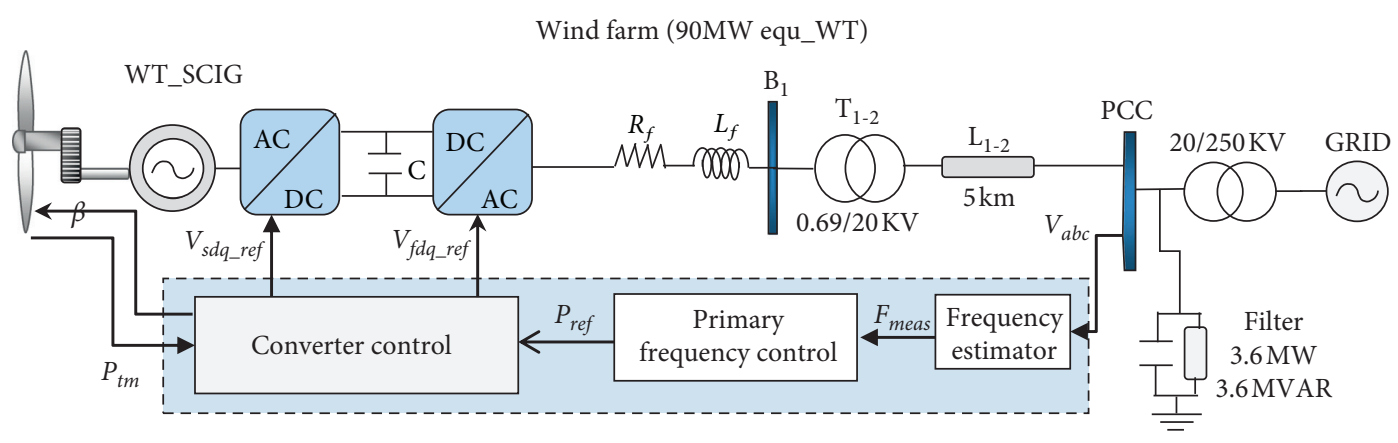

Figure 1: The wind turbine for the primary frequency control.

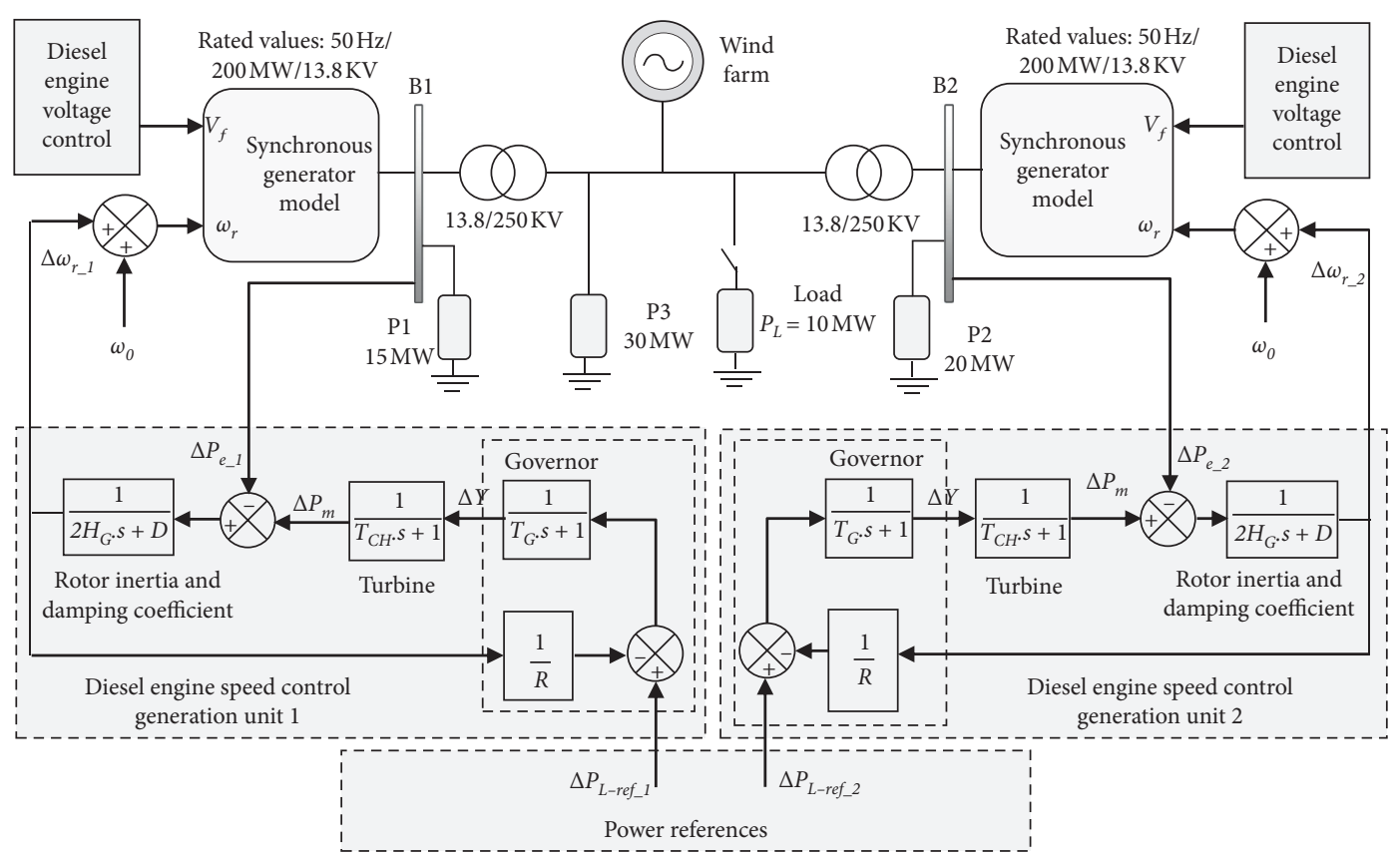

FiguRE 2: Functional block diagram of the two-area power system for primary frequency control.

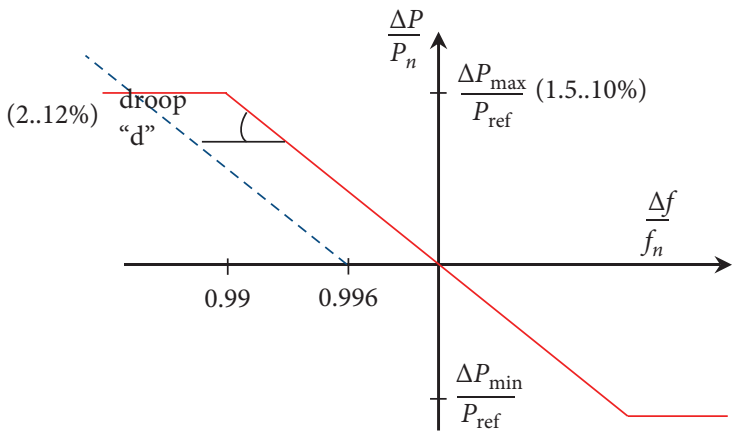

- FSM

-- - LFSM - U

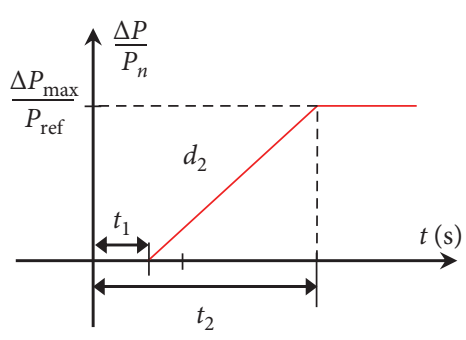

(b)

Figure 3: European grid code requirements ENTSO-E's. (a) Required droop frequency control. (b) The full and initial activation time. 


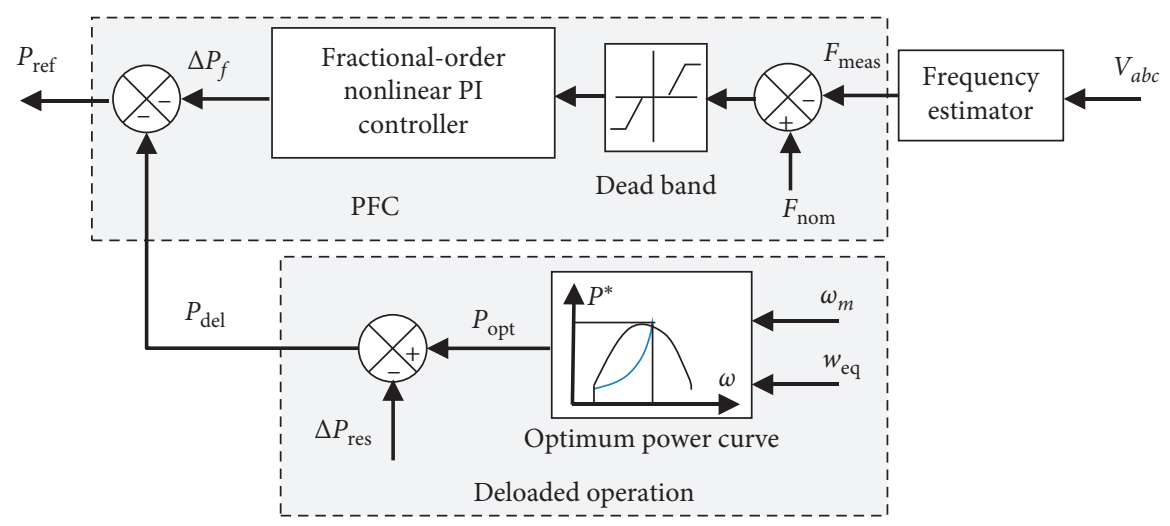

FIGURE 4: Primary frequency control strategy.

$$
D_{t}^{\alpha}= \begin{cases}\frac{\mathrm{d}^{\alpha}}{\mathrm{d} t^{\alpha},} & \alpha>0, \\ \alpha>0, & \alpha=0, \\ \int_{t_{0}}^{t}(d t)^{-\alpha}, & \alpha<0,\end{cases}
$$

where $\lambda \in \mathbb{R}$ is the FO operator.

This operator is applied to a function which leads to the extended Caputo form that is defined for the FO derivative as follows:

$$
D_{t}^{\alpha} f(t)=\frac{1}{\Gamma(m-\alpha)} \frac{d^{m}}{d t^{m}} \int_{t_{0}}^{t} \frac{f(\tau)}{(t-\tau)^{\alpha-m+1}} \mathrm{~d} \tau,
$$

where $m$ is the first integer value greater than $q$ and $(m-1)<\alpha \leq m, m \in \mathbb{N}, t_{0}$ is the initial time, and $\Gamma(\alpha)=$ $\int_{0}^{+\infty} t^{\alpha-1} e^{-t} \mathrm{~d} t$ is the gamma function.

In the design of the proposed fractional-order nonlinear PI controller (6), the FO integral presented in (3) is used.

$$
I_{t}^{\alpha} f(t)=\frac{1}{\Gamma(\alpha)} \int_{t_{0}}^{t} \frac{f(\tau)}{(t-\tau)^{1-\alpha}} \mathrm{d} \tau
$$

Implementation of fractional-order operators is achieved using the CRONE toolbox [50]. Then, FO terms in the proposed controller (4) are approximated using 5-order Oustaloup's modified filter, and the frequency range is set as 0.01 to $100 \mathrm{rad} / \mathrm{s}$.

The Laplace transform of the Caputo fractional derivative integral is given as follows:

$$
L\left\{I_{t}^{\alpha} f(t)\right\}=\frac{F(s)}{s^{\alpha}} .
$$

The design of the nonlinear PI controller can be achieved using the nonlinear function (5):

$$
f(e)=|e|^{r i} \times \operatorname{sign}(e) .
$$

3.3. Nonlinear Fractional Order PI Controller Design. Design of the NL-FO-PI controller is started with the design of the PI controller and the tuning of the PI gains using the trial and error method to obtain the acceptable frequency and active power responses. But the robust design requires the use of the nonlinear PI controller to overcome the problem related to system nonlinearity and disturbances.

For the fast response, the integrator term of the NL-PI controller should be replaced by the fractional-order operator to obtain a robust structure of the NL-FO-PI controller with the superior performance. The superiority is reached using the particle swarm optimization (PSO) algorithm to determine the optimal value of the fractionalorder operator defined in reference [46].

The design layout of the FO-NL-PI controller is based on the structure of the NL function versus the fractional-order integrator, as shown in (6) and illustrated in the bloc scheme of Figure 5, where $k p$ and $k i$ are the proportional gain and the integral gain of the speed controller, sign $(e)$ is the sign function of error, parameters "ri" and "rp" are the exponents of the error absolute value $|e|$, " $\alpha$ " is the operator of the fractional-order integral, and " $s$ " is the operator of Laplace transformation:

$$
\Delta p f=k_{p}\left[|e|^{r i} \times \operatorname{sign}(e)\right]+k_{i}\left[\left|\frac{1}{s^{\alpha}}\right|^{r p} \times \operatorname{sign}\left(\frac{1}{s^{\alpha}}\right)\right] .
$$

\section{Analysis of Control System Response}

From a wind farm point of view, it is difficult to determine the system transfer function of a real power network-connected wind farm because of the unknown droop of the grid generator units, the dynamic of the nonlinear load, and the system complexity. But, approximately, the system transfer function for one grid generator unit can be modeled using the rotor inertia $(M=2 \mathrm{Hg})$ and damping coefficient $(D)$ presented in Figure 2.

The fractional-order operator used in (6) is investigated to adjust the output dynamics for more performance compared to the NL-PI controller, which is the main advantage of the proposed FO-NL-PI controller. Figure 6 presents the feedback system of the integral side controller to understand the effect of the fractional-order operator 


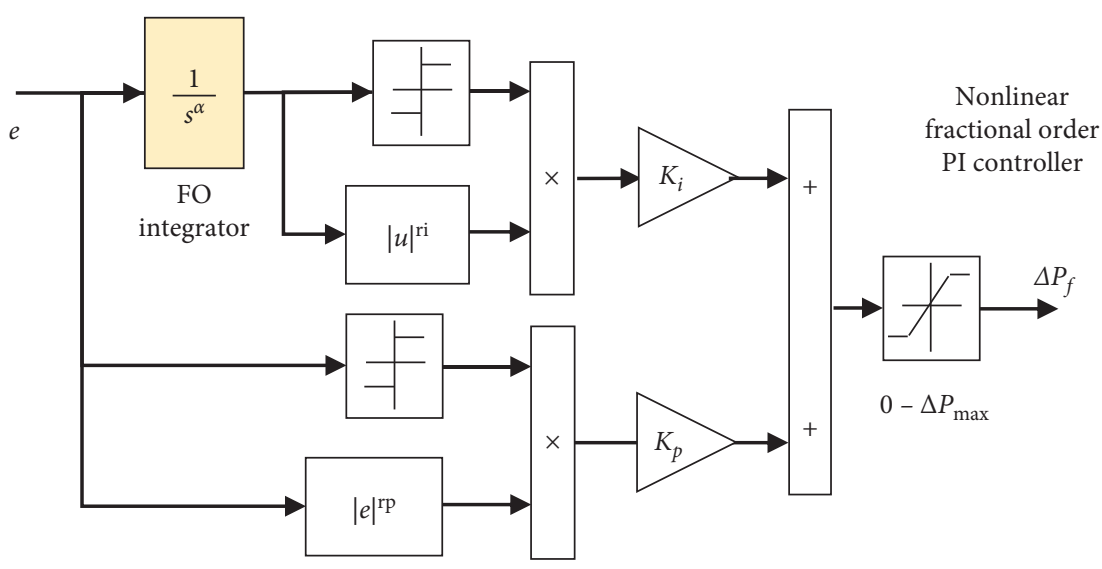

FIgURE 5: Design layout of the NL-FO-PI controller.

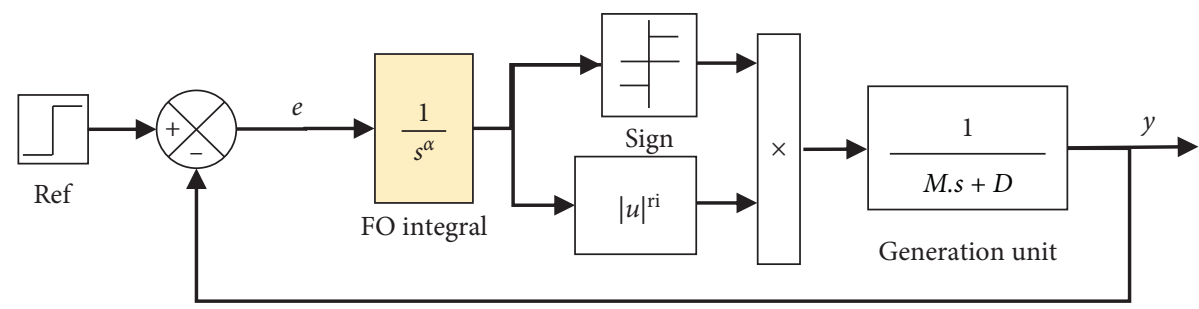

Figure 6: The nonlinear feedback system of the integral side controller.

considering the fractional-order integral and nonlinear function. The output versus time is plotted in Figure 7 for the values of "ri" between 0 and 2, when the variable step is passed through the transfer function of one generator unit.

In order to enhance the performance of control and show the high potential of the FO-NL-PI controller given by the nonlinear term, the NL-PI without integral operator term and gain (ki) should be studied. The step response of the nonlinear function in the closed loop of the nonlinear feedback system given in Figure 8 is plotted in Figure 9 for different values of "ri." From this result, it can be concluded that the accuracy and stability of the nonlinear function are verified for some values of "ri."

4.1. Stability Margins of FO-PI. Stability margins of FO-PI are developed to determine the necessary and sufficient conditions of $\alpha$. From the Bode diagram of Figure 10 and data given in Table 1, it can be seen that, for the positive magnitude margin, the phase margin is positive for limited values of $[0.9,1.4](P m>0)$, which confirms the asymptotic stability of the system in closed loop. For the best stability, the minimum values of the phase margin (Pm) are considered satisfactory around 45 in open loop and 90 in closed loop. These limits can be investigated during the process of the FO-PI controller.

4.2. Step Response of NL-FO-PI. Considering the control system and the speed (frequency in pu) transfer function of the plant, the control feedback system used for the stability analysis and to evaluate the controller response is given in
Figure 11 for the following parameters $M=2 * 3.7, D=1$, $k p=1.1$, and $k i=0.6$.

The output response for different values of $\alpha$ is presented in Figure 12 to show that the controller ensures the best accuracy and the fast response for a specific value of $\alpha$, which makes the NL-FO-PI more efficient than the conventional NL-PI controller. But, the determination of the optimal value of $\alpha$ demands the use of the optimization algorithms to obtain the adequate response [46].

The superiority of the proposed NL-FO-PI controller and the aforementioned analyses study is better understood in a real-example application for primary frequency control as explained in the following section.

\section{Simulation Results for Primary Frequency Control}

Using the wind farm system (Figure 1) connected into the two areas' power system (Figure 2), simulation results are carried out in order to demonstrate the effectiveness of the proposed NL-FO-PI controller performance compared to that given by the conventional FO-PI and NL-PI controllers, which are validated experimentally in the literature [43-45]. The benchmarking process aims to use FO-PI and NL-PI controllers like indicators of performance to evaluate the superiority of the proposed controller in the application of primary frequency control. The PSO functionality is elaborated using MATLAB/Simulink software to optimize the proposed controller parameters. The simulation can be run using the sim command to generate the outputs of the model (current fitness) as explained [46]. 


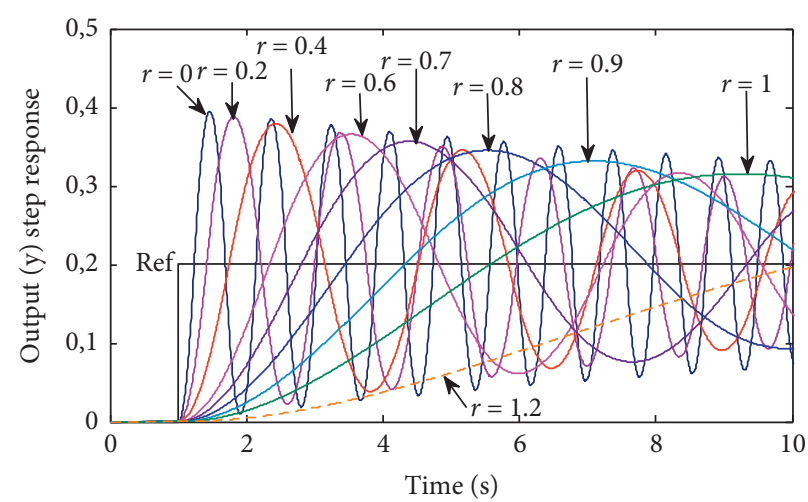

(a)

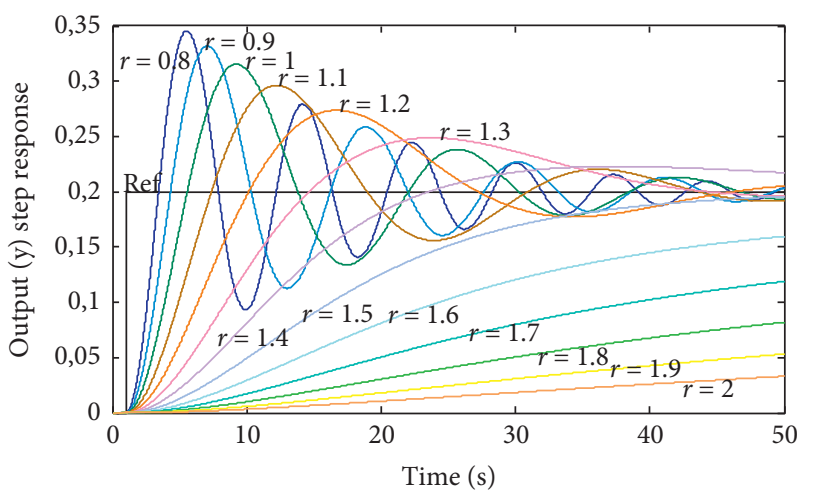

(b)

FIGURE 7: Simulated responses of the integral side of the nonlinear controller versus time when the variable step passed through the transfer function of the one generator unit. (a) " $r$ " varies between 0 and 1.2. (b) " $r$ " varies between 0.8 and 2.

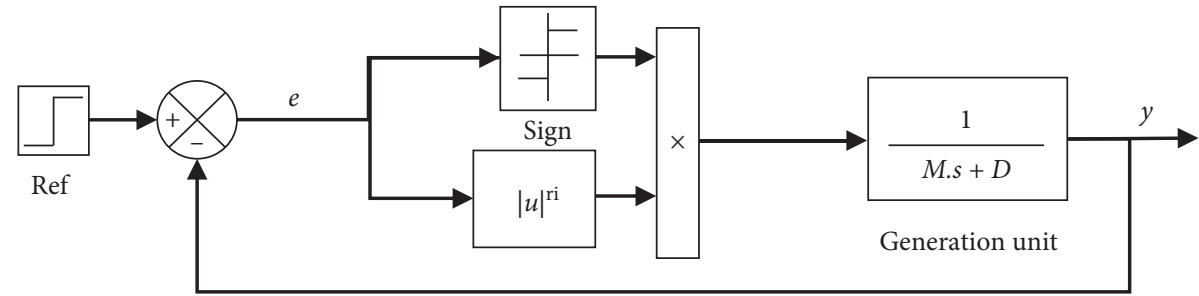

FIGURE 8: The nonlinear feedback system of the nonlinear function.

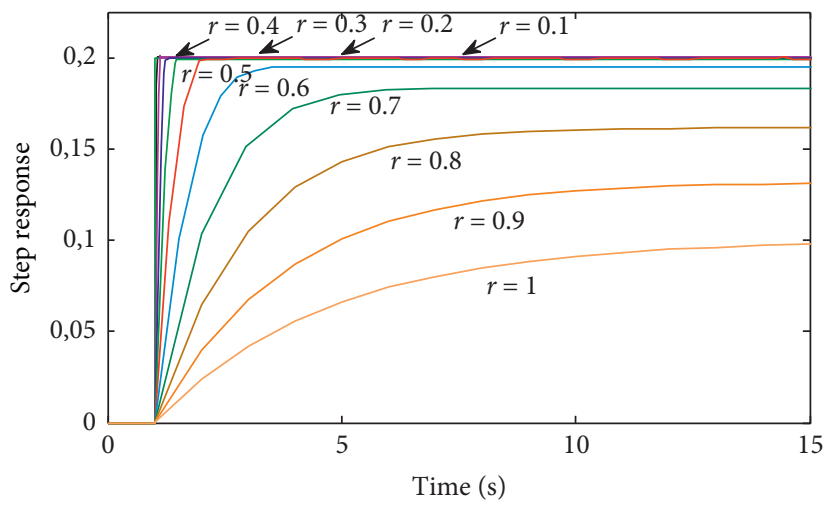

FIGURE 9: Simulated response of the nonlinear function versus time when the variable step is passed through the transfer function of the one generator unit.

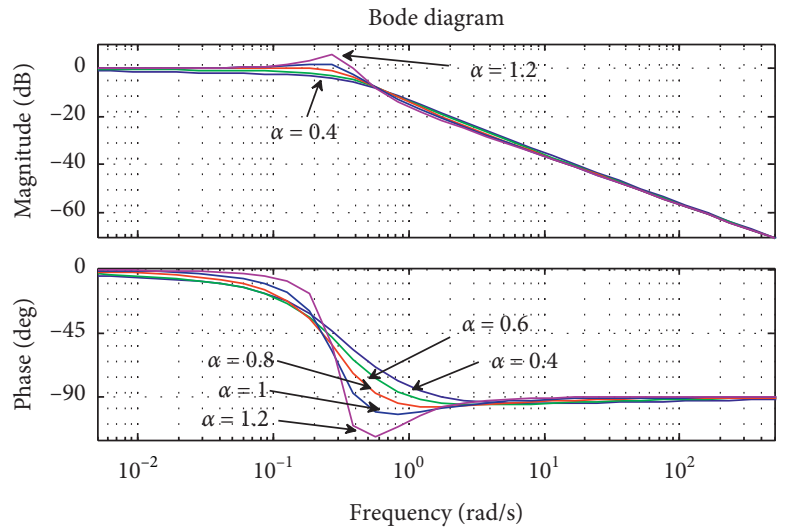

(a)

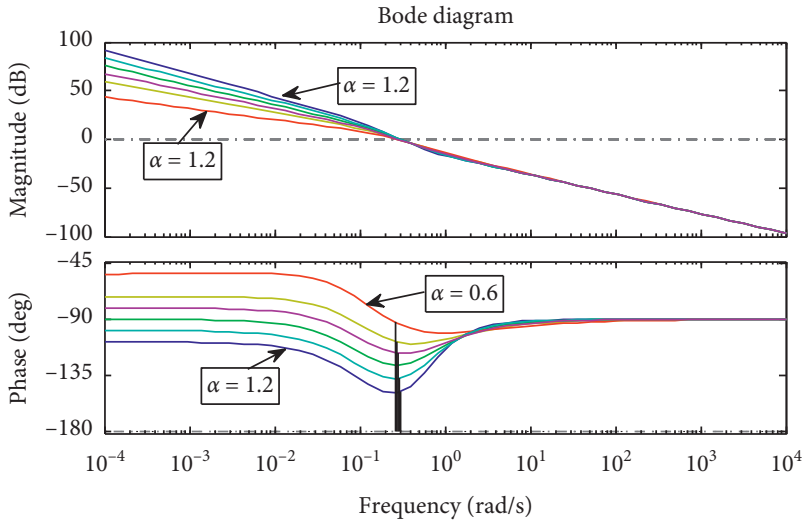

(b)

Figure 10: Bode diagram with FO-PI for different values of $\alpha$. (a) The closed loop. (b) The open loop. 
TABle 1: Phase margin for different values of $\alpha$.

\begin{tabular}{lcc}
\hline$\alpha$ & Pm (open loop) & Pm (closed loop) \\
\hline 1.6 & -17.9050 & -26.5188 \\
1.5 & -4.9190 & 2.7335 \\
1.4 & 7.7496 & 28.6387 \\
1.2 & 31.6473 & 70.9987 \\
1.1 & 42.6631 & 89.1184 \\
1 & 52.9718 & 106.6472 \\
0.9 & 62.5618 & 125.5485 \\
0.8 & 71.4610 & Inf \\
0.6 & 87.4403 & Inf \\
\hline
\end{tabular}

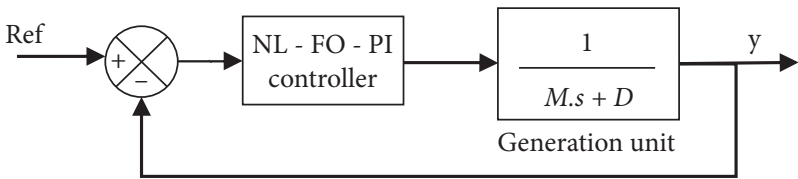

Figure 11: The nonlinear feedback system of the NL-FO-PI controller.

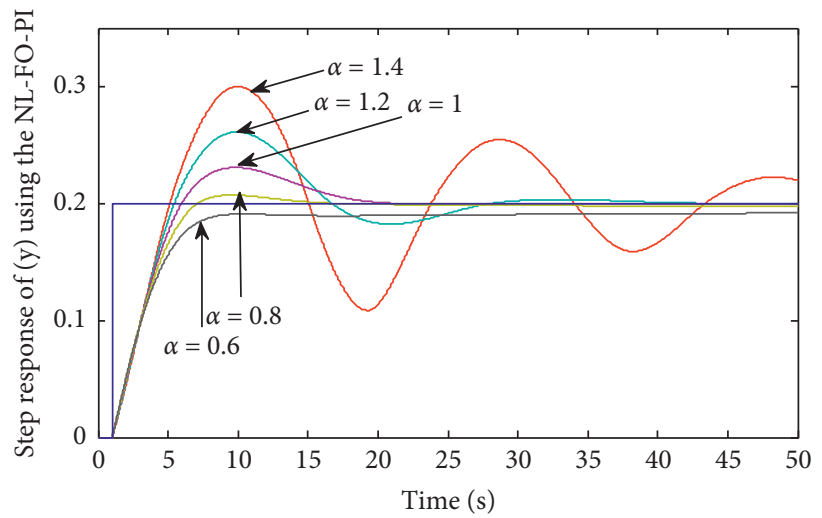

Figure 12: Simulated step responses of the NL-FO-PI controller for different values of $\alpha$.

TABLE 2: Quantitative comparison between the controllers for different performance indexes.

\begin{tabular}{lcccc}
\hline & & Performance indexes & IAE & \\
Controller & ISE & ITSE & 0.2374 & \\
NL-FO-PI & 0.03064 & 0.7819 & 0.2628 & 6.205 \\
NL-PI & 0.03144 & 08042 & 0.2516 & 6.98 \\
FO-PI & 0.0311 & 0.7946 & 6.587 \\
\hline
\end{tabular}

To prove the superior performance of the proposed controller for frequency control, a quantitative comparison is considered based on performance indexes of the integral square error (ISE), the integral time square error (ITSE), the integral absolute error (IAE), and the integral time absolute error (ITAE) defined in [40]. Table 2 shows the comparison based on performance indexes between the proposed NLFO-PI, NL-PI, and FO-PI controllers. From this table, it can be seen that the proposed has excellent performance indexes compared to the other controllers, which are considered as the best ones and have satisfied the criteria of minimum performance indexes. These values of performance indexes demonstrate the minimal deviation from the dead band and best satisfaction of the grid code requirements.
The settling time and the maximum deviation of the frequency-power response, given in Table 3, are derived from Figures 13 and 14. From this table, it can be seen that the immediate response and the minimum deviation from the dead band are offered by the proposed controller.

Figure 15 demonstrates that the proposed controller gives the best performance of mechanical torque, electromagnetic torque, mechanical power, and mechanical speed, in terms of fast response and minimal oscillations. The DC bus voltage (V) uses the two controllers shown in Figure 16. The PCC three-phase voltage and three-phase current presented in Figure 17 are sinusoidal and do not exceed the maximum values. 
TABLe 3: Frequency and active power responses.

\begin{tabular}{lcccc}
\hline & Controller & FOPI & NL-PI & FO-NLPI (proposed) \\
\hline \multirow{2}{*}{ Frequency response } & Maximum deviation from $49.8 \mathrm{~Hz}$ & 0.04 & 0.04 & 0.02 \\
& Settling time $(s)$ acceptable dead band of $0.01 \mathrm{~Hz}$ & 4.5 & 5 & 3.02 \\
\hline \multirow{2}{*}{ Active power response } & Maximum deviation from -67.6 MW & -2.24 & -1.14 & -1.05 \\
& Settling time for stabilization $(s)$ between $[-69,-66]$ & 4.3 & 3.3 & 2.8 \\
\hline
\end{tabular}

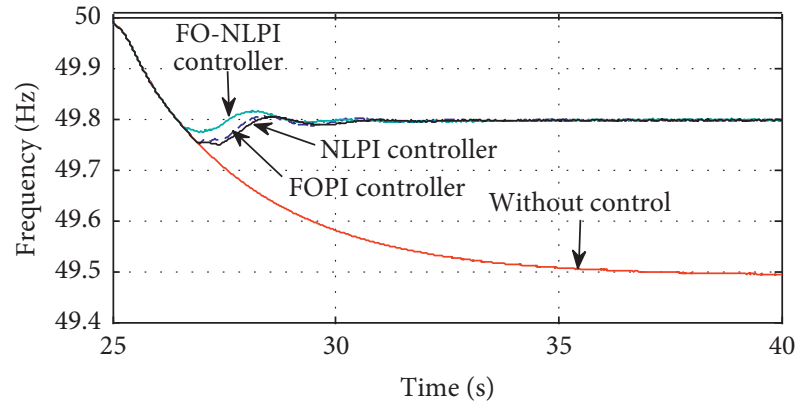

(a)

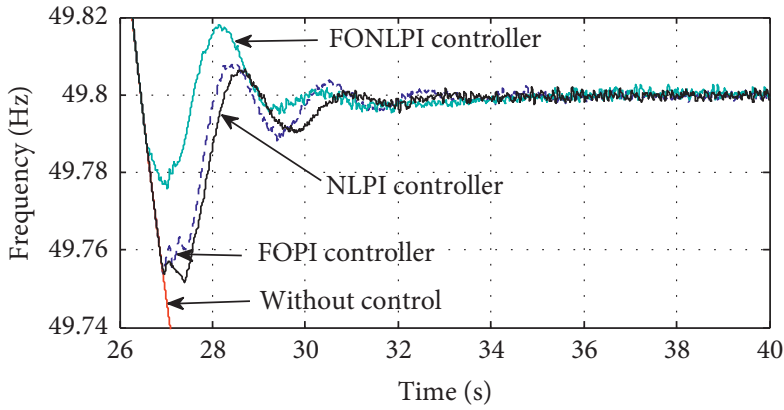

(b)

FIGURE 13: Frequency response (a) using NL-PI and FOIP controller and (b) zoom of frequency response.

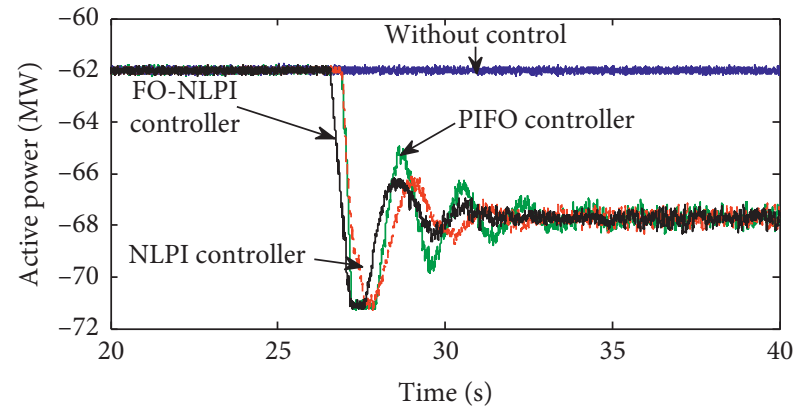

(a)

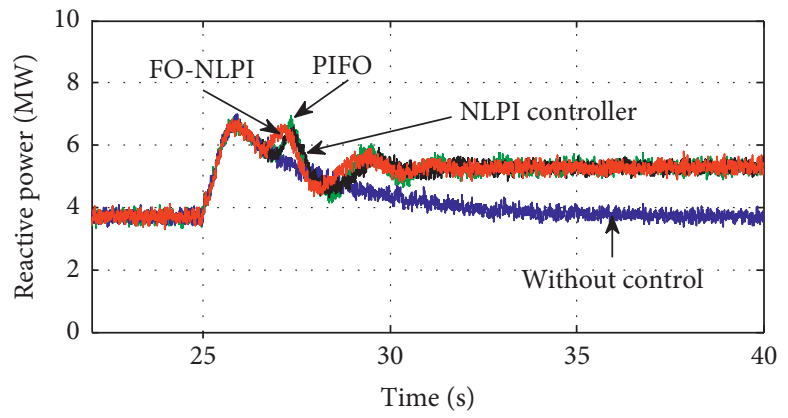

(b)

Figure 14: Power responses. (a) Active power. (b) Reactive power.

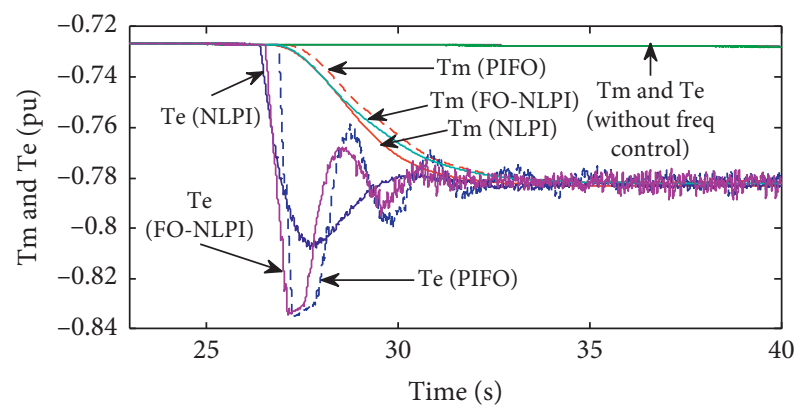

(a)

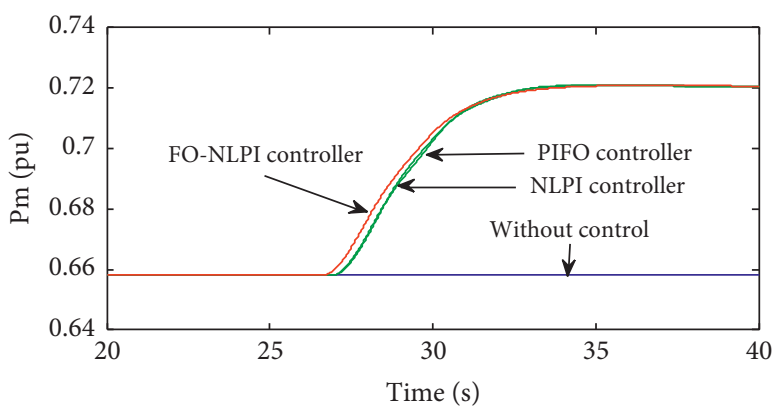

(b)

Figure 15: Continued. 


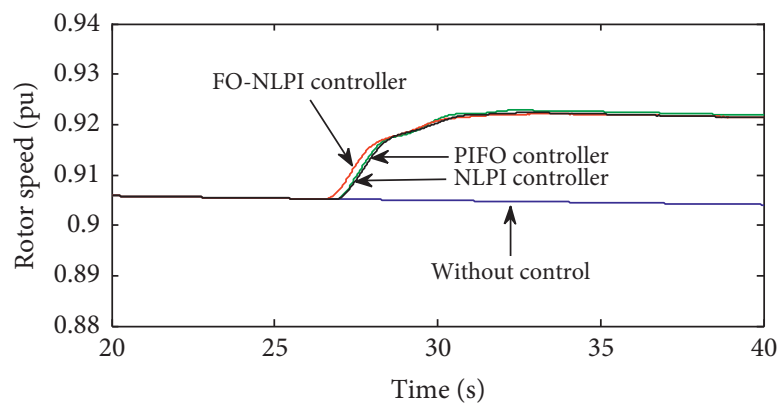

(c)

Figure 15: Mechanical components. (a) Mechanical and electromagnetic torques. (b) Mechanical power and mechanical speed.

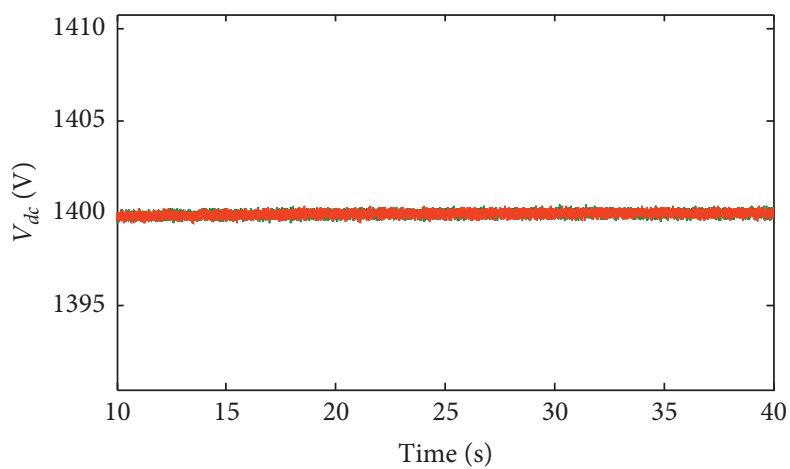

Figure 16: DC bus voltage (V) using the two controllers.

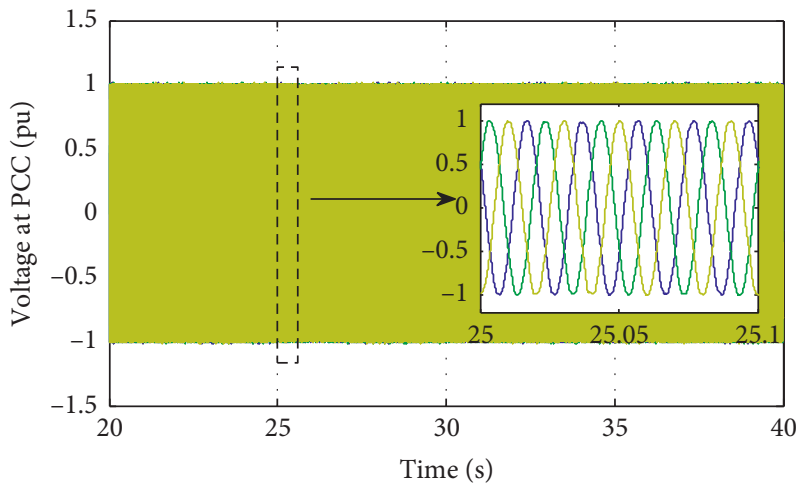

(a)

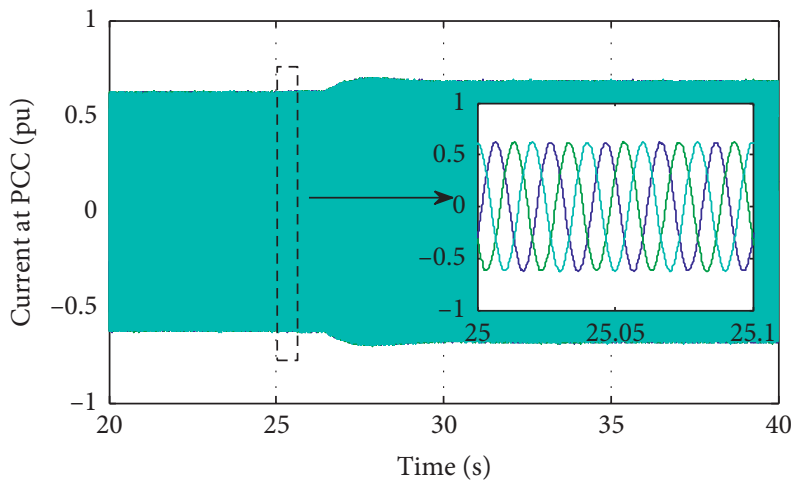

(b)

Figure 17: (a) Three-phase PCC voltage. (b) Three-phase PCC current.

\section{Conclusion}

In this work, a continuous FO-NL-PI control technique has been successfully applied to the wind farm participated in primary frequency control and connected into the two-area power system. The use of nonlinear PI with the fractionalorder integral operator not only improved the grid side power/frequency response but also reduced the time response of the wind turbine mechanical components. Simulation results demonstrated the effectiveness of the proposed controller and showed robustness in improving the frequency stability under a $10 \%$ step increase of active load demand. It is observed that the proposed controller has the following characteristics:

(i) Ensures the minimal performance indexes, which means that the minimum frequency deviation outside the dead band of $[49.8,50]$

(ii) Satisfies the grid code requirements for frequency control

(iii) Improves settling time of the system to achieve the maximum deviation of frequency and power 


\section{Data Availability}

No data were used to support this study.

\section{Conflicts of Interest}

The authors declare that they have no conflicts of interest.

\section{References}

[1] F. Díaz-González, M. Hau, A. Sumper, and O. Gomis-Bellmunt, "Participation of wind power plants in system frequency control: review of grid code requirements and control methods," Renewable and Sustainable Energy Reviews, vol. 34, pp. 551-564, 2014.

[2] K. Elyaalaoui, M. Ouassaid, and M. Cherkaoui, "Primary frequency control using hierarchal fuzzy logic for a wind farm based on SCIG connected to electrical network," Sustainable Energy, Grids and Networks, vol. 16, pp. 188-195, 2018.

[3] Y. Arya, "Effect of electric vehicles on load frequency control in interconnected thermal and hydrothermal power systems utilising CF-FOIDF controller," IET Generation, Transmission \& Distribution, vol. 14, no. 114, pp. 2666-2675, 2020.

[4] K. Elyaalaoui, M. Ouassaid, and M. Cherkaoui, "Dispatching and control of active and reactive power for a wind farm considering fault ride-through with a proposed pi reactive power control," Renewable Energy Focus, vol. 28, no. 100, pp. 56-65, 2019.

[5] C. Guo and D. Wang, "Frequency regulation and coordinated control for complex wind power systems," Complexity, vol. 2019, p. 12, 2019.

[6] S. G. Varzaneh, M. Abedi, and G. B. Gharehpetian, "Constant power control of variable speed wind farm for primary frequency control support," Energy Systems, vol. 10, no. 1, pp. 163-183, 2018.

[7] ENTSO-E, "Entso-e network code for requirements for grid connection applicable to all generators, [En ligne]," 2016.

[8] Y. Arya, "Effect of energy storage systems on automatic generation control of interconnected traditional and restructured energy systems," International Journal of Energy Research, vol. 43, no. 12, pp. 6475-6493, 2019.

[9] K. Elyaalaoui, M. Ouassaid, and M. Cherkaoui, "Improvement of THD performance of a robust controller for grid-side energy conversion system based on LCL filter without RC sensor," International Journal of Electrical Power \& Energy Systems, vol. 121, 2020.

[10] M. Ouassaid, K. Elyaalaoui, and M. Cherkaoui, "Sliding mode control of induction generator wind turbine connected to the grid," in Advances and Applications in Nonlinear Control Systems, pp. 531-553, Springer, Cham, Switzerland, 2016.

[11] W. Tan, S. Chang, and R. Zhou, "Load frequency control of power systems with non-linearities, IET Generation," Transmission \& Distribution, vol. 11, no. 117, pp. 4307-4313, 2017.

[12] S. Sondhi and Y. V. Hote, "Fractional order PID controller for load frequency control," Energy Conversion and Management, vol. 85, pp. 343-353, 2014.

[13] A. A. Dastjerdi, B. M. Vinagre, Y. Chen, and S. H. HosseinNia, "Linear fractional order controllers; A survey in the frequency domain," Annual Reviews in Control, vol. 47, pp. 51-70, 2019.

[14] H. Mahvash, S. A. Taher, M. Rahimi, and M. Shahidehpour, "DFIG performance improvement in grid connected mode by using fractional order [PI] controller," International Journal of Electrical Power \& Energy Systems, vol. 96, pp. 398-411, 2018.

[15] M. Labbadi, Y. Boukal, and M. Cherkaoui, "Path following control of quadrotor UAV with continuous fractional-order super twisting sliding mode," Journal of Intelligent \& Robotic Systems, vol. 100, no. 13, pp. 1429-1451, 2020.

[16] R. K. Naidu and S. Meikandasivam, "Power quality enhancement in a grid-connected hybrid system with coordinated PQ theory \& fractional order PID controller in DPFC," Sustainable Energy, Grids and Networks, vol. 21, 2020.

[17] A. Beddar, H. Bouzekri, B. Babes, and H. Afghoul, "Experimental enhancement of fuzzy fractional order PI+I controller of grid connected variable speed wind energy conversion system," Energy Conversion and Management, vol. 123, pp. 569-580, 2016.

[18] A. Asgharni, R. Shahnazi, and A. Jamali, "Performance and robustness of optimal fractional fuzzy PID controllers for pitch control of a wind turbine using chaotic optimization algorithms," ISA Transactions, vol. 79, pp. 27-44, 2018.

[19] R. Vikhram, Yohanandhan, and L. Srinivasan, "Decentralised wide-area fractional order damping controller for a large-scale power system, IET Generation," Transmission \& Distribution, vol. 10, no. 15, pp. 1164-1178, 2017.

[20] R. Melicio, V. Mende, and J. Cataliio, "Wind energy systems with power-electronic converters and fractional-order controllers," in Proceedings of the 5th IET International Conference on Power Electronics, Machines and Drives (PEMD 2010), Brighton, UK, April 2010.

[21] T. Mahto and V. Mukherjee, "Fractional order fuzzy PID controller for wind energy-based hybrid power system using quasi-oppositional harmony search algorithm," IET Generation, Transmission \& Distribution Journal, The Institution of Engineering and Technology, vol. 11, no. 113, pp. 3299-3309, 2017.

[22] T. Vigya, T. Mahto, H. Malik, V. Mukherjee, M. A. Alotaibi, and A. Almutairi, "Renewable generation based hybrid power system control using fractional order-fuzzy controller," Energy Reports, vol. 7, pp. 641-653, 2021.

[23] D. M. S. Almutairi, "Modified salp swarm algorithm-optimized fractional-order adaptive fuzzy PID controller for frequency regulation of hybrid power system with electric vehicle," Journal of Control, Automation and Electrical Systems, vol. 32, pp. 416-438, 2021.

[24] O. Maroufi, A. Choucha, and L. Chaib, "Hybrid fractional fuzzy PID design for MPPT-pitch control of wind turbinebased bat algorithm," Electrical Engineering, vol. 102, no. 4, pp. 2149-2160, 2020.

[25] B. Herissi and D. Boudjehem, "Fractional-order fuzzy controller for a PMSG wind turbine system wind turbine system," International Journal of Systems Science, vol. 21, no. 116, pp. 3237-3250, 2020.

[26] Y. Arya, "Impact of ultra-capacitor on automatic generation control of electric energy systems using an optimal FFOID controller," International Journal of Energy Research, vol. 43, no. 114, pp. 8765-8778, 2019.

[27] M. S. Ayas, "Design of an optimized fractional high-order differential feedback controller for an AVR system," Electrical Engineering, vol. 101, no. 4, pp. 1221-1233, 2019.

[28] V. Phat, P. Niamsup, and M. V. Thuan, "A new design method for observer-based control of nonlinear fractional-order systems with time-variable delay," European Journal of Control, vol. 56, pp. 124-131, 2020.

[29] L. Chen, G. Chen, R. Wu, A. M. Lopes, J. A. T. Machado, and H. Niu, "Variable coefficient fractional-order PID controller 
and its application to a SEPIC device," IET Control Theory \& Applications, vol. 14, no. 16, pp. 900-908, 2020.

[30] L. Chen, G. Chen, P. Li, A. M. Lopes, J. T. Machado, and S. Xu, "A variable-order fractional proportional-integral controller and its application to a permanent magnet synchronous motor," Alexandria Engineering Journal, vol. 59, no. 15, pp. 3247-3254, 2020.

[31] I. Pan and S. Das, "Fractional order fuzzy control of hybrid power system with renewable generation using chaotic PSO," ISA Transactions, vol. 62, pp. 19-29, 2016.

[32] D. Pathak and P. Gaur, "A fractional order fuzzy-proportional-integral-derivative based pitch angle controller for a direct-drive wind energy system," Computers \& Electrical Engineering, vol. 78, pp. 420-436, 2019.

[33] K. Xu, L. Chen, M. Wang, A. M. Lopes, J. A. Tenreiro Machado, and H. Zhai, "Improved decentralized fractional PD control of structure vibrations," Mathematics, vol. 8, no. $13,2020$.

[34] F. Merrikh-Bayat and M. Afshar, "Extending the root-locus method to fractional-order systems," Journal of Applied Mathematics, vol. 2008, Article ID 528934, 2008.

[35] M. Rivero, S. V. Rogosin, J. A. T. Machado, and J. J. Trujillo, "Stability of fractional order systems," Mathematical Problems in Engineering, vol. 2013, Article ID 356215, 2013.

[36] V. C. Elik, M. T. O. Zdemir, and K. Y. Lee, "Effects of fractional-order PI controller on delay margin in single-area delayed load frequency control systems," Journal of Modern Power Systems and Clean Energy, vol. 7, no. 12, pp. 380-389, 2019.

[37] R. Lamba, S. K. Singla, and S. Sondhi, "Design of fractional order PID controller for load frequency control in perturbed two area interconnected system," in Electric Power Components and Systems, pp. 1-14, Taylor \& Francis Group, Abingdon, UK, 2019.

[38] U. Thakar, V. Joshi, and V. Vyawahare, "Design of fractionalorder PI controllers and comparative analysis of these controllers with linearized, nonlinear integer-order and nonlinear fractional-order representations of PMSM," International Journal of Dynamics and Control, vol. 5, no. 1, pp. 187-197, 2017.

[39] G. C. Konstantopoulos and P. R. Baldivieso-Monasterios, "Nonlinear PI controller for systems with state constraint requirements," in Proceedings of the 2019 18th European Control Conference (ECC), Naples, Italy, June 2019.

[40] F. Merrikh-Bayat and N. Mirebrahimi, "Introduction to the nonlinear PI $\lambda D \mu$ control," in Proceedings of the IEEE International Conference on Control System, Computing and Engineering, Penang, Malaysia, November 2011.

[41] X.-J. Wen, Z.-M. Wu, and J.-G. Lu, "Stability analysis of a class of nonlinear fractional-order systems," IEEE Transactions on Circuits and Systems-II: Express Briefs, vol. 55, no. 111, pp. 1178-1182, 2008.

[42] A. Pisano, M. Rapaic, Z. Jeliči, and E. Usai, "Nonlinear fractional PI control of a class of fractional-order systems," IFAC Proceedings Volumes, vol. 45, no. 13, pp. 637-642, 2012.

[43] V. Yousefzadeh and S. Choudhury, "Nonlinear digital PID controller for DC-DC converters," in Proceedings of the Twenty-Third Annual IEEE Applied Power Electronics Conference and Exposition, Austin, TX, USA, February 2008.

[44] P. Roy and B. Krishna Roy, "Fractional order PI control applied to level control in coupled two tank MIMO system with experimental validation," Control Engineering Practice, vol. 48, pp. 119-135, 2016.
[45] Y. Jin, Y. Luo, C. Wang, and Y. Chen, "LabVIEW based experimental validation of fractional order motion controllers," in Proceedings of the 2009 Chinese Control and Decision Conference, Piscataway, NJ, USA, June 2009.

[46] K. Elyaalaoui, M. Labbadi, M. Ouassaid, and M. Cherkaoui, "Optimal fractional order based on fuzzy control scheme for wind farm voltage control with reactive power compensation," Mathematical Problems in Engineering, vol. 2021, Article ID 5559242, 2021.

[47] L. M. Fernández, C. A. García, J. R. Saenz, and F. Jurado, "Equivalent models of wind farms by using aggregated wind turbines and equivalent winds," Energy Conversion and Management, vol. 50, no. 3, pp. 691-704, 2009.

[48] A. M. S. Al-bayati, F. Mancilla-David, and J. L. Dominguez-Garcia, "Aggregated models of wind farms: current methods and future trends," in Proceedings of the North American Power Symposium (NAPS), IEEE, Denver, CO, USA, September 2016.

[49] H. Holttinen, M. Milligan, E. Ela, N. Menemenlis, and J. Dobschinski, "Methodologies to determine operating reserves due to increased wind power," IEEE Transactions on Sustainable Energy, vol. 3, no. 14, pp. 713-723, 2012.

[50] A. Tepljakov, E. Petlenkov, and J. Belikov, "FOMCON: fractional-order modeling and control toolbox for MATLAB," in Proceedings of the 18th International Conference Mixed Design of Integrated Circuits and Systems, pp. 684-689, Wrocław, Poland, June 2011. 